\title{
Superior Anatomic Visualisation of a Large Intracardiac Metastasis of a Uterine Leimyosarcoma by Cardiac Magnetic Resonance Imaging with Important Implications for Therapeutic Strategies
}

\author{
Achim BARMEYER ${ }^{1}$, Nerbil KILIC ${ }^{2}$, Oliver ZANTIS $^{1}$ Cagri DEMIR $^{1}$, Kai MUELLERLEILE ${ }^{1}$, \\ Gunnar LUND ${ }^{3}$, Bjoern NASHAN ${ }^{4}$, Volker DOERING ${ }^{5}$, Ralf KOESTER ${ }^{1}$, \\ Ergin KILIC ${ }^{6}$, Thomas MEINERTZ ${ }^{1}$ \\ University Hospital Hamburg-Eppendorf, Department of Cardiology/Angiology \\ ${ }^{2}$ University Hospital Hamburg-Eppendorf, II. Department of Internal Medicine \\ ${ }^{3}$ University Hospital Hamburg-Eppendorf, Diagnostic and Interventional Radiology Department and Clinic \\ ${ }^{4}$ University Hospital Hamburg-Eppendorf, Department of Hepatobiliary and Transplant Surgery \\ ${ }^{5}$ University Hospital Hamburg-Eppendorf, Department of Cardiovascular Surgery \\ ${ }^{6}$ University Hospital Hamburg-Eppendorf, Department of Pathology, Hamburg, GERMANY
}

\section{ABSTRACT}

In a 41-year old woman with history of a uterine leimyosarcoma, a large intracardiac tumor was found by computerized tomography scan and further characterized by echocardiography and cardiac magnetic resonance imaging. Imaging results made it possible to operatively excise the tumor during circulatory arrest.

Keywords: Intracardiac metastasis of uterine leiomyosarcoma, MRI, Cardiac surgery

\section{ÖZET}

Kardiyak MRI ile Uterin Leiomyosarkomunun Intrakardiyak Metastazının Daha İyi Görüntülenmesi ve Tedavi Stratejisinin Belirlenmesine Etkisi

Uterin leiomyosarkomu olan 41 yaşında bayanda bilgisayarlı tomografi analizinde kalbi dolduran büyük bir tümör saptanmıştır. Hasta ekokardiyografi ve kadiyak manyetik rezonans görüntüleme ile yeniden değerlendirilmiştir. Elde edilen görüntüler yardımıyla tümör çıkarımıştır.

Anahtar Kelimeler: Kalpte uterin leiomyosarkom metastazı, Kardiyak MRI, Kalp cerrahisi 


\section{INTRODUCTION}

The adequate therapy for a singular intracardiac tumor is operative removal. However, imaging with information on structure and extension of the tumor, its mobility and its adhesion to cardiac and extracardiac structures are crucial for the planning of procedural details. We report on a case, where cardiac magnetic resonance imaging made it possible to remove a large tumor with hepatic and cardiac involvement.

\section{CASE REPORT}

A 41-year-old woman with history of a uterine leiomyosarcoma was admitted for restaging. Four months ago, she had undergone extensive surgery comprising hysterectomy, adnexectomy, omentectomy, lymphadenectomy and partial resection of the small intestine. She was asymptomatic and had recovered well from the operation. However, the computerized tomography (CT) scan revealed an expansive lesion in liver segment IV with evidence

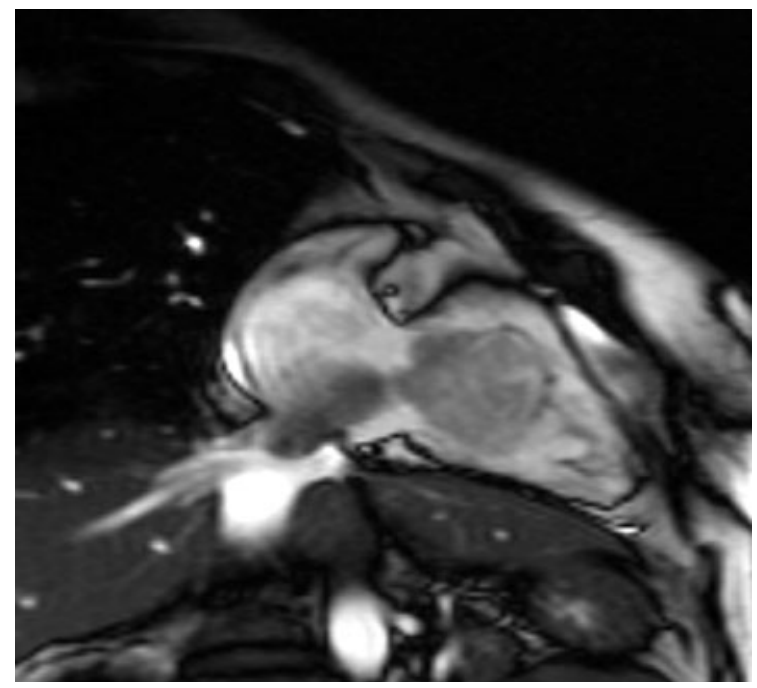

Figure 2a. Magnetic resonance cine-imaging of the intracardiac part of the tumor. The right cardiac long axis view shows both parts of the waisted tumor. The proximal part emerges from the inferior caval vein and shows no site of adhesion to the atrial wall. It is attached to a tumorous chord originating from the left hepatic lobe. In diastole the tumorous chord is stretched and seen on the roof of the left hepatic vein and the infradiaphragmatic part of the caval vein. The distal part of the intracardiac tumor prolapses into the the right ventricle in diastole and is repelled into the right atrium in systole.

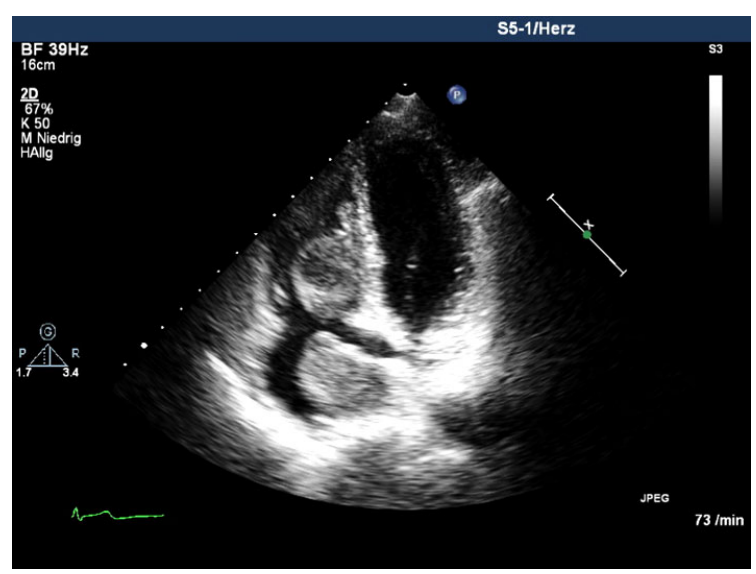

Figure 1. Transthoracic echocardiography showing the intracardiac part of the tumor in four-chamber-view. Due to the limited mobility of the right atrial part of the tumor it can not be determined, whether it is adherent to cardiac structures.

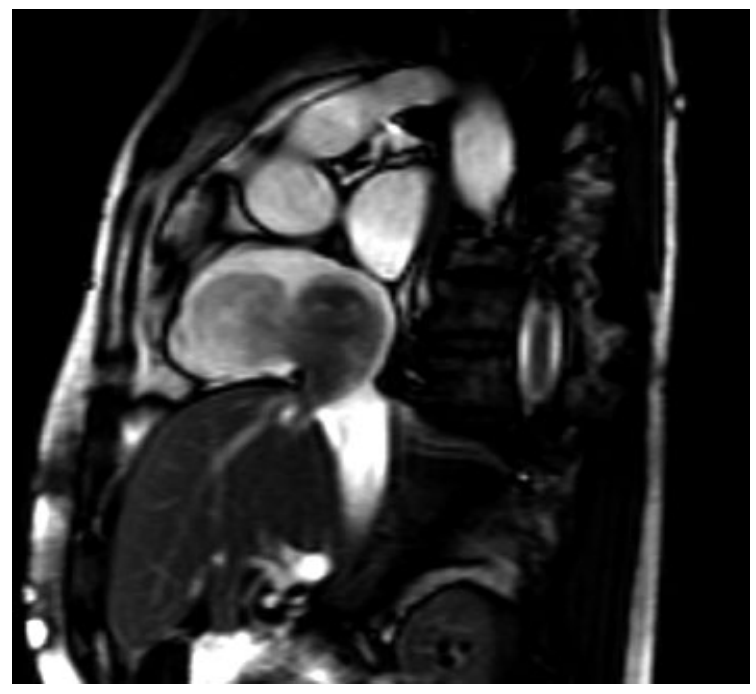

Figure 2b. A sagittal view of the right atrium shows the proximal part of the intracardiac tumor which is clearly non-adherent to the atrial wall. The tumorous chord emerging from the left hepatic vein and inferior caval vein is seen below. 


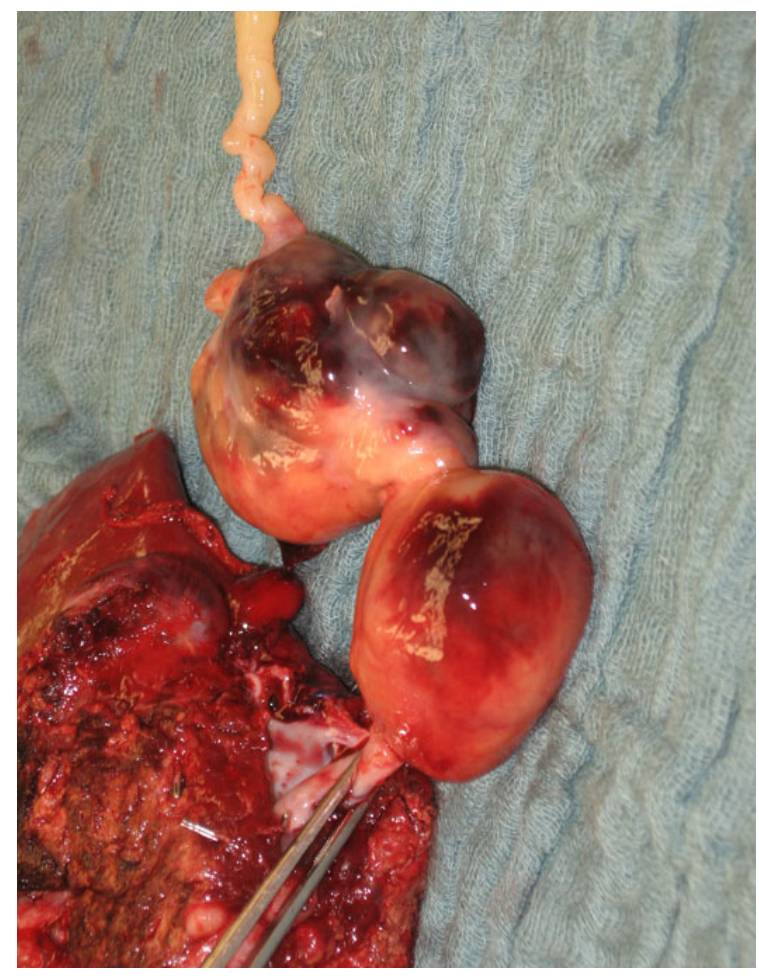

Figure 3. Preparation of the left hepatic lobe with the tumorous chord (held by the surgical forceps) emerging from the left hepatic vein and the inferior caval vein (exposed above the tumorous chord) with the intracardiac waisted part of the leiomyosarcoma. Proximal parts of the distal tumorous appendice are seen on the right side of the picture. The solid, waisted part of the tumor measured $8.8 \times 5 \times 4 \mathrm{~cm}$, the length of the appendice was $12 \mathrm{~cm}$. No site of adhesion was found on the surface of the tumor. RA: right atrial part; RV: right ventricular part; RVOT: right ventricular outflow tract (RVOT).

of tumorous material in the inferior caval vein and a large tumorous mass in the right cardiac cavities. No other evidence of metastatic disease was found. To examine the intracardiac lesion further, transthoracic echocardiography (TTE) was performed. It demonstrated an elongated solid tumor consisting of a waisted bulky part filling out considerable parts of the right atrial and right ventricular cavity and a thin appendix extending into the right-ventricular outflow-tract but not reaching across the pulmonary valve (Figure 1). The proximal end of the waisted part of the tumor was located in the right atrium showing only little mobility. From TTE it could not be concluded whether it was adherent to the endocardium or not. The distal end of the wais- ted part demonstrated high mobility with diastolic prolaps into the right ventricle and systolic repulsion into the right atrium. To evaluate whether the atrial part of the intracardic tumor was adherent to the endocardium a cardiac magnetic resonance imaging (MRI) was performed. By use of cine-imaging it could be demonstrated that the proximal intracardiac part of the tumor was attached to a tumorous chord emerging from the inferior caval vein (Figure 2a). The mobility of the proximal intracardiac part of the tumor shown in several planes in MRI indicated no adherence to the endocardium (Figure 2b). Due to the acute risk of embolism and obstruction, respectively, and no other evidence of further metastasis, the decision was taken to operate on the tumor. The operation was conducted by a team of liver surgeons and cardiac surgeons. After preparation of the thoracic and abdominal situs with left hemihepatectomy and provisional preservation of the left and middle liver vein, hypothermia was induced. Circulatory arrest was then established and the left and middle liver veins were excised from the inferior caval vein preserving the tumorous chord. At the same time, the right atrium was opened towards the inferior caval vein and the intracardiac part of the tumor was pulled out easily through the combined opening and retrieved together with the hepatic lobe (Figures 3). Caval vein and right atrium were sutured and circulation was reestablished after 8 minutes. The histopathological examination of the tumor diagnosed a lowly differentiated uterine leiomyosarcoma with the same immunohistological characterization as before. The patient recovered from the operation without complications.

\section{DISCUSSION}

The uterine leiomyosarcoma is a rare tumor which is mostly found in uterine myomas. The metastatic pattern of leiomyosarcomas shows a high preference for hematogenous dissemination(1). Metastases are mostly parenchymatous and intravascular growth is less frequent. However, cardiac metastasis secondary to uterine leimyosarcoma are extremely rare and are commonly diagnosed postmortem. ${ }^{2}$ The therapy of choice of a singular metastasis is surgical removal. In the case of our patient it was crucial for the surgical proceedings whether the tu- 
mor was adherent to endocardial structures or not. MRI is a cardiovascular imaging modality that combines superior visualisation of endocardial borders and free choice of imaging planes and provides 3-dimensional information on the mobility and adherence of visualized structures. Operative excision of an intravenous leiomyosis with intraabdominal and cardiac involvement has already been reported to be made possible by MRI. ${ }^{3}$ In our patient the surgical proceedings in the rare case of a leimyosarcoma with hepatic and cardiac involvement also could only be determined after proof of freedom from adherence by MRI. Thus, cardiac MRI is helpful in the characterization of intracardiac tumors and can guide therapeutic strategies.

\section{REFERENCES}

1. Platz CE, Benda JA. Female genital tract cancer. Cancer 75:270-294, 1995

2. Calleja AM, Wellnitz CV, Alharthi MS, Khandheria BK, Chaliki HP. Extensive cardiac metastases secondary to uterine leiomyosarcoma. J Am Soc Echocardiogr 22:1419 e1415-1417, 2009.

3. Uchida H, Hattori Y, Nakada K, Lida T. Successful one-stage radical removal of intravenous leiomyomatosis extending to the right ventricle. Obstet Gynecol 103:1068-1070, 2004.

\section{Correspondence}

Nerbil KILIC

Department of Medical Oncology

University Hospital Basel

Petersgraben 4,

4057 Basel, Switzerland

Phone: ++41-61-3286099

Fax: ++41-61-2659037

e-mail: nkilic@uhbs.ch 